\title{
A DEEP LEARNING BASED SLEEPNESS AND WAKEFULNESS DETECTION FOR DRIVERS
}

\author{
Şahin IŞIK ${ }^{1}$, Yıldıray ANAGÜN2² \\ ${ }^{1}$ Eskișehir Osmangazi University, Engineering and Architecture Faculty, Computer Engineering Department, Eskișehir, \\ ORCID No: http://orcid.org/0000-0003-1768-7104 \\ ${ }^{2}$ Eskişehir Osmangazi University, Engineering and Architecture Faculty, Computer Engineering Department, Eskişehir, \\ ORCID No: https://orcid.org/0000-0002-7743-0709
}

\begin{tabular}{ll}
\hline Keywords & Abstract \\
\hline Deep Learning, & Falling asleep while driving is a major part of road accidents. Traffic accidents can be \\
Driver Sleepiness Detection, & considered as a public health problem and several factors like drugs, driving without rest, \\
Electrocardiogram, & sleep disorders, alcohol consumption affect sleep deprivation. Furthermore, drivers are \\
Staying Awake, & also unaware of falling asleep situations, such as highway hypnosis. All these factors \\
Driving & cause accidents while driving and are often fatal. A good background should be provided \\
& for drivers to implement effective driver warning systems and other countermeasures \\
just before the accident. In this study, Long-Short Term Memory (LSTM) based driver & warning system has been proposed to prevent road accidents. The Electrocardiogram \\
& (ECG) signals are processed instantaneously to check whether they go into sleep or not. \\
Experimental studies have been carried out on two different human data sets as sleep \\
mode and awake mode. The \%95.52 accuracy rate confirms the effectiveness of the \\
proposed method and show its superiority over some state-of-the art methods.
\end{tabular}

\section{SÜRÜCÜLER İÇIN DERİN ÖĞRENME TABANLI YORGUNLUK VE UYUŞUKLUK} TESPITI

\begin{tabular}{l}
\hline Anahtar Kelimeler \\
\hline \\
Derin Öğrenme, \\
Sürücü Uyku Hali Tespiti, \\
Elektrokardiyogram, \\
Uyanık Kalmak, \\
Araç Sürme
\end{tabular}

Araştırma Makalesi

Başvuru Tarihi

Kabul Tarihi

\section{Öz}

Sürüș sırasında uyumak, trafik kazalarının önemli bir parçasıdır. Trafik kazaları bir halk sağlı̆̆ı sorunu olarak değerlendirilmekle beraber uyuşturucu, dinlenmeden araç kullanma, uyku bozukluklarl, alkol tüketimi gibi çeşitli faktörler uykusuzluğu etkilemektedir. Ayrıca sürücüler, otoyol hipnozu gibi uykuya dalma durumunun da farkına varmayabilirler. Tüm bu faktörler, sürüș sırasında kazalara neden olur ve genellikle ölümcüldür. Sürücülerin kazadan hemen önce etkili sürücü uyarı sistemleri ve diğer karşı önlemleri uygulamaları için etkili yöntem sağlanmalıdır. Bu çalışmada, trafik kazalarını önlemek için Uzun-Kısa Süreli Hafıza (LSTM) tabanlı sürücü uyarı sistemi önerilmiştir. Elektrokardiyogram (EKG) sinyalleri, uykuya geçip geçmediklerini kontrol etmek için anlık olarak işlenmektedir. Uyku halinde ve uyanık halde olmak üzere iki farklı insan veri seti üzerinde deneysel çalışmalar yapılmıştır. \%95.52 doğruluk sonucu, önerilen yöntemin etkinliğini kanıtlamakta ve bazı klasik teknoloji yöntemlere göre üstünlüğünü göstermektedir.

\section{Introduction}

In the 21st century, the drowsy driving is known as the one of most important cause of accidents. Although it is ignored and underestimated, in fact, it is a dangerous factor contributing to accidents. There are different

$\begin{array}{ll}\text { Research Article } & \\ \text { Submission Date } & : 04.03 .2021 \\ \text { Accepted Date } & : 19.08 .2021\end{array}$

drawbacks of driving a car more than 8 or 9 hours, such as serious hearty issues begin due to fatigue and distraction which affects the driving performance and raises the accident risk. Research shows that significant deterioration in driving performance initiated as a

*Sorumlu yazar; e-posta : yanagun@ogu.edu.tr

$\mathrm{Bu}$ eser, Creative Commons Attribution License (http://creativecommons.org/licenses/by/4.0/) hükümlerine göre açık erişimli bir makaledir.

This is an open access article under the terms of the Creative Commons Attribution License (http://creativecommons.org/licenses/by/4.0/). 
result of on average more than 16 hours of sleep deprivation. This situation poses serious dangers in terms of traffic safety.

A crowded set of systems have been developed to integrate some automated mechanisms into cars to obtain information about the sleep level of the driver. One of such system has developed by the Panasonic Company (Panasonic), aimed to measure the sleep level without the need for any physical contact, only relied on applying artificial intelligence to the obtained information from the camera, vehicle information and various sensors while the car is on the road.

In this system, the mimics of the driver such as facial movements and frequency of blinking are employed in the first phase. In the second stage, the temperature level, the movements of the wheel and the speed of the car are processed to accurately determine the drowsiness on driving. Moreover, the body temperature of a driver is measured with thermal sensors and inserted to the equation related to drowsiness level detection. As a key contribution of this study, we can rank the mental state of driver with four levels; sleepless, less sleepy, drowsy, very drowsy and seriously drowsy. Eventually, the system gives an alert as soon as detecting the risk case and warns the driver with a message about resting.

As an example of another study, the Ford Company (Ford, 2020) designed a smart hat for truck drivers that prevents falling asleep. The smart hat, namely SafeCap, records and processes the head movements of the driver. From the measured recordings, it detects that the driver is sleeping or going to sleep. To avoid the accident risk, it warns the driver to pull over. Technically, the system works on the basis of head movements. If the tiny sensors integrated into the hat detects that the person's head is tilted vertically or horizontally at a certain angle for a certain period of time, then it warns with an alarm.

As another intelligent study, called the Harken Project (Harken, 2020), was carried out by the Biomechanics institute. The main purpose of the system is detecting whether the driver is sleeping or not by monitoring the heart and respiratory rhythms with the smart materials placed in the seat belt and seat cover.

Recently, various research studies have explored the efficacy of the machine learning for biomedical signal analysis, in particular for sleep, drowsiness and wakefulness detection tasks. Chui, Tsang, Chi, $\mathrm{Wu}$ and Ling (2015) developed a biometric-signals-based method for driver drowsiness detection with Support Vector Machine (SVM). Jeong, Yu, Lee and Lee (2019) used a deep spatio-temporal convolutional bidirectional long short-term memory network (DSTCLN) model on Karolinska sleepiness scale (KSS) values to classify two mental states and five drowsiness levels. Radha, Fonseca, Moreau, Ross, Cerny, Anderer, Long \& Aarts
(2019) analyzed Hearth Rate Value (HRV) based sleep stage classification with a long short-term memory (LSTM) network. Shahrudin and Sidek (2020) applied Machine Learning (ML) tools on QRS complexes Işık, Özkan and Ergin (2019), which are recovered from the ECG signal with a purpose of drowsiness detection. Also, Chaabene et al. (2021) utilized a convolutional neural network (CNN) model as a solution for drowsiness detection.

Upon inspecting theoretic backgrounds and some of aforementioned methods, one can observe that they are relied on the traditional approaches. On the other hand, the recently developed ones, called deep learning-based approaches, produce more successful results than traditional methods. Inspiring from this fact, we have conducted experimental simulations with the deep learning based methods to detect the sleep and wakefulness of a person. For this purpose, we have utilized a robust time series based deep learning approach, namely LSTM, implemented with Keras Library on PYTHON (KERAS). The proposed system is holds various advantages over other systems. These advantages can be listed as:

- Accessibility: We offline trained the proposed LSTM model and it can be used universally. We will share our trained LSTM model on GitHub. In this way, anyone will be able to use them for commercial or Research and development (R\&D) purposes.

- Portability: Our model will be easy to integrate into a mobile application or an embedded system. Therefore, our model has a portable and mobility feature.

- Domesticity Contribution: In addition, we will make a contribution to national software with developed system.

- Economic: A low cost and high performance model can be developed with our system.

- Baby-driven: The proposed system can expanded for detecting sleep level of baby and giving alarm when the baby is crying.

- Customer-driven: Moreover, the proposed system can be used to monitor health of elder people or disability persons.

- Communication: The recommended system can communicate with the family of drivers by forwarding a simple message.

- Universality: The proposed system can be used in all countries and for different human races.

The remaining parts of this manuscript is divided into three subsections. The second subsection gives details and settings utilized in proposed deep learning model. The third subsection explains the performance and compared to other methods. Finally, a conclusion is given to summarize the method. 


\section{Materials and Methods}

There are two different datasets in our study. The first one is ECG data about the sleeping mode of persons, while the second one is for Awaking mode. In the Sleep Bioradiolocation Database (Goldberger, Amaral, Glass, Hausdorff, Ivanov, Mark, Mietus, Moody, Peng \& Stanley, 2000; Tataraidze, Korostovtseva, Anishchenko, Bochkarev, Sviryaev \& Ivashov, 2016), there are 32 ECG samples, which were recorded with contactless sleep monitoring by a bioradar. The recorded duration of each ECG sample is about 60 minutes. There are five stages about a sleeping mode, which are summarized as:

- W: wakefulness

- 1 : stage 1

- 2: stage 2

- 3: stage 3

- R: REM

The given sleep stages were annotated by an expert, who is a certified physician based on polysomnography (Embla N7000) with respect to the rules of the American Academy of Sleep Medicine. It was emphasized that there is no sleep disordered breathing and related sleep movements in samples.

Another dataset holds the ECG samples of awaking persons, which is widely known as MIT-BIH Arrhythmia Database (MITDB) (Goldberger et al., 2000; Moody and Mark, 2001). The MITDB includes 47 samples of ECG records and duration of the each record is about 30 minutes, which accounts to 1800 seconds.

The objective of this study is to make predictions about the sleeping and awaking modes of a person on the basis of time series based deep learning model. For this purpose, we have employed the LSTM model on ECG data. For all experiments, we have used a simple LSTM model, which is implemented in Keras Library of Python programming language. The utilized LSTM is consisting of only 1 layer. The parameter setting of utilized LSTM model is given in Table 1 .
Table 1

Parameter Details of LSTM

\begin{tabular}{lc}
\hline Parameter Name & Value \\
\hline Number of epochs & 20 \\
Batch size & 128 \\
Input length & 300 \\
Learning rate & $1 \mathrm{e}-3$ \\
Activation function & Sigmoid \\
Loss function & Binary cross-entropy \\
Optimizer & RMSprop \\
\hline
\end{tabular}

Prior to training the LSTM, an appropriate preprocessing process is greatly required for pattern recognition tasks. We also applied a convenient preprocessing stage in this study.

The sampling frequency of each dataset is given as $50 \mathrm{~Hz}$ and $360 \mathrm{~Hz}$ for Sleepbrl and MITDB, respectively. Dimension of one ECG signal data is about $1 \times 650000$ and $1 \times 162000$, for MITDB and Sleepbrl. For MITDB dataset, the dimension of 1 second ECG segment $(650000 /(360 * 30))$ is equal to $1 \times 60$. Also, for Sleepbrl dataset, the dimension of 1 second ECG $(162000 /(60 * 50))$ segment is $1 \times 54$. Therefore, we can specify the dimension of an ECG record as $1 \times 300$, which refers to training the LSTM model with almost 5 seconds ECG record. Similarly, for test stage, we have used 5 seconds ECG record. Awake and sleepy status data are rescale to 0-1 range by using min-max normalization and the obtained normalized coefficients are forward to LSTM model for training. The authors declared that research and publication ethics were followed in this study.

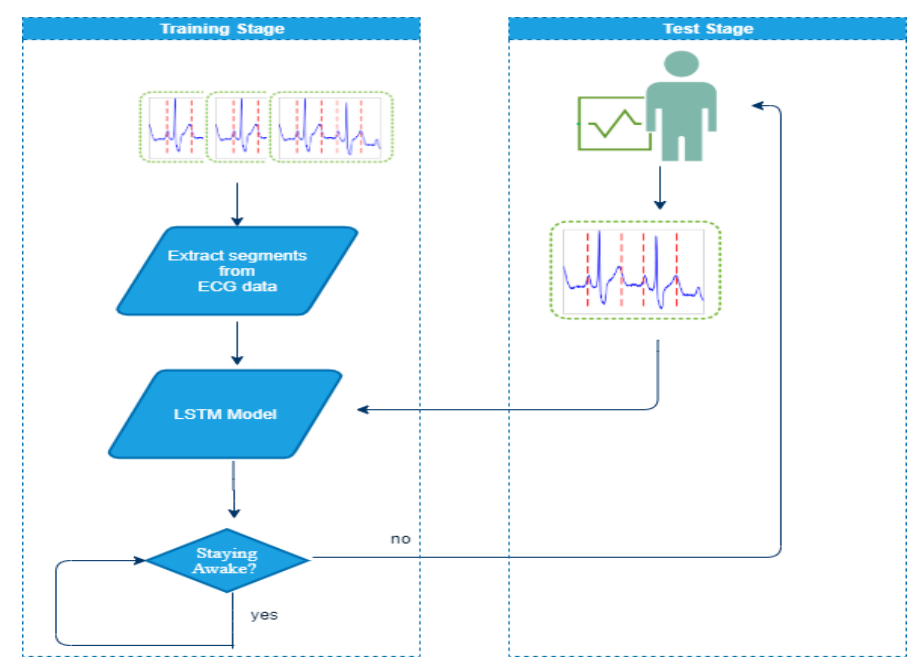

Figure 1. Schematic Drawing Of The Wakefulness Detection System. 


\section{Experimental Studies}

For this study, we have divided ECG records of 47 awaking and 32 sleeping persons into nearly equal duration distinct segments. In total, we have used the 8,129 segments for training and 2,033 segments for testing the performance of our system. As explained above, the segment length of each record is $1 \times 300$. The test samples consisted of 762 awaking records and 1271 sleeping records.

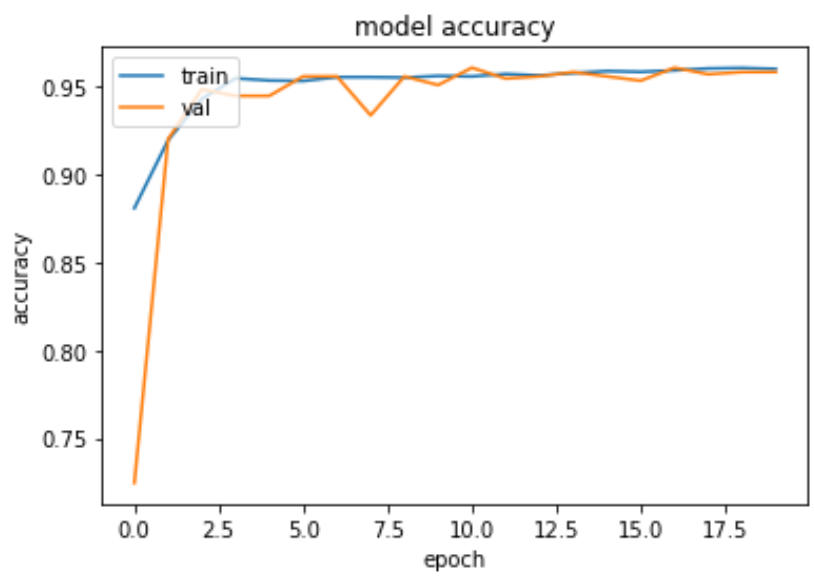

Figure 2. Performance Of The Model During Stage.

Figure 2 denotes performance of the proposed model obtained during the training phase. The $\% 10$ of data was reserved for validation purpose. One can observe that the validation performance is about $\% 96.06$.

Table 2

Performance Comparison With State-Of-The-Art Methods

\begin{tabular}{|c|c|c|c|}
\hline Name & Tool & Method & Accuracy $(\%)$ \\
\hline $\begin{array}{l}\text { (Chaabene } \\
\text { et al., 2021) }\end{array}$ & EEG & CNN & 90.42 \\
\hline $\begin{array}{l}\text { (Chui et al., } \\
\text { 2015) }\end{array}$ & $\begin{array}{c}\text { ECG } \\
\text { Heartbeat }\end{array}$ & SVM & 76.93 \\
\hline $\begin{array}{l}\text { (Jeong et } \\
\text { al., 2019) }\end{array}$ & EEG & Bi-LSTM & 87.00 \\
\hline $\begin{array}{l}\text { (Shahrudin } \\
\text { and Sidek, } \\
2020 \text { ) }\end{array}$ & ECG & Regression & 92.00 \\
\hline $\begin{array}{l}\text { (Radha et } \\
\text { al., 2019) }\end{array}$ & ECG & LSTM & 77.00 \\
\hline Proposed & ECG & LSTM & 95.52 \\
\hline
\end{tabular}

Table 2 presents the performance of some state of art methods for normal, drowsy and sleepy detection on the basis of ECG data and a camera. Chaabene et al. (2021) considered a convolutional neural network (CNN) architecture for drowsiness detection. Performance of the system was reported with an accuracy rate of 90.42\%. Similarly, the normal driving ECG dataset and drowsy ECG dataset are utilized as the heartbeat segments are extracted and classified with Support Vector Machine (SVM) classifier (Chui et al., 2015). The performance is about 77\% in terms of accuracy metrics. Moreover, a deep spatio-temporal convolutional bidirectional long short-term memory network (DSTCLN) model applied on electroencephalography (EEG) signals for detecting five pilot's drowsiness levels (Jeong et al. 2019). For two states, alert and drowsy states (2-class), the $87 \%$ average accuracy performance was achieved with DSTCLN architecture. Also, a logistic regression based approach (Babaeian, Bhardwaj, Esquivel and Mozumdar, 2016; Shahrudin and Sidek, 2020) was applied on ECG data to detect driver drowsiness at the early stage. With logistic regression, the over $92 \%$ accuracy result was obtained from ECG data. Finally, a recent study (Radha et al., 2019) has also validated the performance of LSTM on detecting the cardiac sleep architecture information. The accuracy rate is reported to $77 \%$ over 195 healthy and 97 patients.

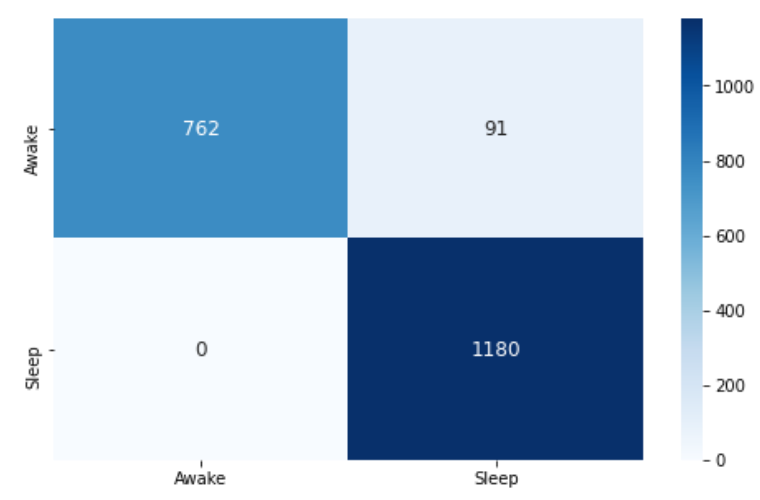

Figure 3. Confusion Matrix Of Test Samples.

The Figure 3 presents the confusion matrix obtained from two classes including Awake and Sleep. In overall, the system performance over test samples was recorded with an accuracy rate of \%95.52 for 762 awaking records and 1271 sleeping records. This obtained nice performance can be explained that it is very easy to observe the difference between ECG beats of sleeping and awaking samples after applying the deep learning concept. 


\section{Conclusions}

In this study, a method has been presented that can detect whether drivers are awake or sleepy in real time. The proposed algorithm is based on the time series based deep learning model, namely LSTM.

It is possible to use the implemented work on mobile or on the web. If data acquired from the wristband or any ECG sensor to the cloud, the algorithm would successfully processes the data. However, wristbands for capturing and saving data to the cloud are relatively expensive.

\section{Contribution of Researchers}

Şahin IŞIK contributed to the publication with the coding and writing of the article. In addition, the author performed the CNN model design. For this purpose, LSTM model was used on ECG data. Yıldıray ANAGÜN contributed to study, evaluation of methods and discussion of results and review of the article.

\section{Conflict of Interest}

No conflict of interest was declared by the authors.

\section{References}

Babaeian, M., Bhardwaj, N., Esquivel, B., \& Mozumdar, M. (2016, November). Real time driver drowsiness detection using a logistic-regression-based machine learning algorithm. In 2016 IEEE Green Energy and Systems Conference (IGSEC) (pp. 1-6). IEEE. Doi: https://doi.org/10.1109/IGESC.2016.7790075

Chaabene, S., Bouaziz, B., Boudaya, A., Hökelmann, A., Ammar, A., \& Chaari, L. (2021). Convolutional Neural Network for Drowsiness Detection Using EEG Signals. Sensors, 21(5), 1734. Doi : https://doi.org/10.3390/s21051734

Chui, K. T., Tsang, K. F., Chi, H. R., Wu, C. K., \& Ling, B. W. K. (2015, July). Electrocardiogram based classifier for driver drowsiness detection. In 2015 IEEE 13th International Conference on Industrial Informatics (INDIN) (pp. 600-603). IEEE. doi: https://doi.org/10.1109/INDIN.2015.7281802.

Ford (2020). Retrieved from https://bolha.com.br/work/ford-safe-cap/

Goldberger, A. L., Amaral, L. A., Glass, L., Hausdorff, J. M., Ivanov, P. C., Mark, R. G., Mietus, J. E., Moody, G. B., Peng C. K. \& Stanley, H. E. (2000). PhysioBank, PhysioToolkit, and PhysioNet: components of a new research resource for complex physiologic signals. circulation, 101(23), e215-e220. doi: https://doi.org/10.1161/01.cir.101.23.e215
Harken (2020). Retrieved from http://harken.ibv.org/

Işık, Ş., Özkan, K. and Ergin, S., (2019). Biometric person authentication framework using polynomial curve fitting-based ECG feature extraction. Turkish Journal of Electrical Engineering \& Computer Sciences, 27(5), 3682-3698. doi:10.3906/elk-1901-168. doi: https://doi.org/10.3906/elk-1901-168

Jeong, J. H., Yu, B. W., Lee, D. H., \& Lee, S. W. (2019). Classification of drowsiness levels based on a deep spatio-temporal convolutional bidirectional LSTM network using electroencephalography signals. Brain sciences, $9(12), \quad 348$. doi: https://doi.org/10.3390/brainsci9120348

KERAS. Retrieved on from https://keras.io/

Moody, G. B. and Mark, R. G., (2001). The impact of the MIT-BIH arrhythmia database. IEEE Engineering in Medicine and Biology Magazine, 20 (3), 45-50. doi: https://doi.org/10.1109/51.932724

Panasonic. Retrieved from https://www.gzt.com/ teknoloji/panasonicten-muthis-teknolojidireksiyon-basinda-uyumaya-son-2769871

Radha, M., Fonseca, P., Moreau, A., Ross, M., Cerny, A., Anderer, P., Long, X. \& Aarts, R. M. (2019). Sleep stage classification from heart-rate variability using long short-term memory neural networks. Scientific reports, 9(1), 1-11. $\quad$ https://doi.org/10.1038 /s41598-019-49703-y

Shahrudin, N. N. and Sidek, K. (2020). Driver drowsiness detection using different classification algorithms, Journal of Physics: Conference Series, IOP Publishing. doi: https://doi.org/10.1088/1742-6596/1502/ $\underline{1 / 012037}$

Tataraidze, A., Korostovtseva, L., Anishchenko, L., Bochkarev, M., Sviryaev, Y., \& Ivashov, S. (2016, August). Bioradiolocation-based sleep stage classification. In 2016 38th Annual International Conference of the IEEE Engineering in Medicine and Biology Society (EMBC) (pp. 2839-2842). IEEE. doi: https://doi.org/10.1109/EMBC.2016.7591321 